\title{
Synthesis of Silica-Salen Derivative from Rice Husk Ash and its Use for Extraction of Divalent Metal Ions Co(II), Ni(II) and Cu(II)
}

\author{
Duha Hussien Attol and Hayder Hamied Mihsen ${ }^{*}$ \\ Department of Chemistry, College of Science, University of Kerbala, Karbala 56001, Iraq
}

* Corresponding author:

email: hayderalhmedat@gmail.com

Received: September 4, 2018

Accepted: December 29, 2018

DOI: $10.22146 / \mathrm{ijc} .38558$

\begin{abstract}
Rice husk ash (RHA) was used to prepare sodium silicate, which in turn was functionalized with 3-(chloropropyl)triethoxysilane employing the sol-gel technique to form RHACCl. Chloro group in RHACCl was replaced with iodo group forming RHACI. Ethylenediamine was immobilized on RHACI in order to prepare it for the reaction with salicylaldehyde to form a silica derivative-salen. FT-IR analysis indicated the presence of secondary amine and $-\mathrm{NH}$ and $\mathrm{C}=\mathrm{N}$ absorption bands. XRD analysis revealed the occurrence of the broad diffused peak with maximum intensity at $22-23^{\circ}(2 \theta)$. BET measurements showed also that the surface area of the prepared compound is $274.55 \mathrm{~m}^{2} / \mathrm{g}$. Elemental analysis proved the existence of nitrogen in the structure of the prepared compound. The silica derivative-salen showed high potential for extraction and removal of heavy contaminating metal ions $\mathrm{Ni}$ (II), $\mathrm{Cu}(\mathrm{II})$, and $\mathrm{Co}(\mathrm{II})$ from aqueous solutions. The kinetic study demonstrates that the adsorption of the metal ions follows the pseudo-second order.
\end{abstract}

Keywords: amorphous silica; salicylaldehyde; surface area; preconcentration process; uptake capacity

\section{- INTRODUCTION}

In recent years there has been considerable interest in developing silica-based porous materials that have large specific surface areas. This is due to widespread applications in white light emission process [1], battery applications [2], antibacterial activity [3-4], heavy metal ions separation and extraction [5-12], and catalysis [1316]. Rice is one of the silica producing plants, where the major $\mathrm{SiO}_{2}$ content is observed in its husk, which ranges from 8.7 to $28 \%$ depending on several factors including origin, geographic location and climate [2,17]. Rice husk $(\mathrm{RH})$ is the protective coat of rice grains. As reported by Govindarao [18], RH constituents on a dry basis are ash (20\%), cellulose (38\%), lignin (22\%) and organic compounds (20\%). Rice husk ash (RHA) ash is silica representing (94\%) of the whole [19]. Preconcentration of trace metals employing functionalized silica-gel has received much attention in the last few decades. Preliminary experiments were conducted by Leyden and Lutterll [20] and Leyden et al. [21] using amine, dithiocarbamate, and thioether derivatives for preconcentration process. Recently, this topic was a subject of extensive research, and a variety of functionalized silica compounds were prepared in order to extract or separate metal ions from aqueous solutions [6,11,22-25].

In this work, silica derivative-salen was synthesized from RH via sol-gel technique and nucleophilic substitution reaction. The resultant material was characterized using FTIR, XRD, CHNS, SEM-EDS, AFM, TGA and BET. The metal uptake capacity of the functionalized silica was investigated using aqueous solutions of $\mathrm{Ni}(\mathrm{II}), \mathrm{Co}(\mathrm{II})$ and $\mathrm{Cu}(\mathrm{II})$ metal ions. The effect of several factors on the preconcentration process was examined as well as including time of shaking, the concentration of metal ions, the mass of the ligand and $\mathrm{pH}$ of the solution.

\section{- EXPERIMENTAL SECTION}

\section{Materials}

Sodium hydroxide (BHD, England 99\%), nitric acid ( $\mathrm{CDH}$, India 70\%), 3-chloropropyltriethoxysilane 
(Sigma, Germany 99\%), Acetone (Romal 99.7\%), ethylenediamine (ALPHA CHEMICA, India 99\%), triethylamine (CDH, India 98\%), salicylaldehyde (CDH, India 99\%), Nickle chloride hexahydrate (BDH, England 96\%), Cobalt chloride hexahydrate (BDH, England 97\%), Copper chloride dihydrate (BDH, England 97\%), Toluene (Merk, KGaA, Germany 99\%). All the chemicals were used as received without further purification.

\section{Procedure}

\section{Characterization techniques}

Functional groups in functionalized silica were determined using a Thermo AVATAR instrument. The spectra were recorded in the range of $4000-400 \mathrm{~cm}^{-1}$. Scanning Electron Microscopy (SEM) analysis of functionalized silica was conducted on a FESEM MIRA III (TESCAN). Samples were dispersed in ethanol for 10 min before analysis. Atomic Force Microscopy (AFM) analysis was conducted on an AFM Angstrom AA-3000.

Thermogravimetric (TG) analysis was performed using a TA Q600 instrument. The sample was heated from 50 to $600{ }^{\circ} \mathrm{C}$ at a heating rate of $20^{\circ} \mathrm{C} \mathrm{min}{ }^{-1}$ under $\mathrm{Ar}$ atmosphere. The X-ray Diffraction (XRD) patterns were obtained using Shimadzu X-ray Diffractometer using $\mathrm{CuKa}$, and $2 \theta$ between 10 and $80^{\circ}$. Surface area and pore volume of the sample were measured by BrunauerEmmett-Teller using BEL BELSORP MINI II instrument. Elemental analysis was performed using a Thermo Finnigan FlashEA 1112 instrument.

\section{Extraction and functionalization of silica from $R H$}

Extraction of silica from RH. RH was washed with water then rinsed with distilled water then dried at room temperature for $24 \mathrm{~h}$. Afterward, the sample was stirred with $(1.0 \mathrm{M})$ nitric acid at room temperature for $24 \mathrm{~h}$, then washed with distilled water. Subsequently, the wet material dried at $100{ }^{\circ} \mathrm{C}$ for $24 \mathrm{~h}$. To obtain amorphous silica, the sample was calcined at $750^{\circ} \mathrm{C}$ for $2 \mathrm{~h}$ in a muffle furnace to obtain acid leached RHA [26].

Functionalization of RHA with 3-(chloropropyl) triethoxysilane (CPTES). Functionalization of RHA was done in accordance with the procedure described by Adam et al. [27]. Silica obtained from RHA was stirred with $\mathrm{NaOH}$ in a plastic container at $80^{\circ} \mathrm{C}$ for $60 \mathrm{~min}$ to convert silica into sodium silicate, then CPTES was added to this solution. Next, the solution was titrated with 3.0 $\mathrm{M}$ of nitric acid until the $\mathrm{pH}$ of the solution dropped to 3 . The obtained gel was aged for 2 days, then centrifuged with water profusely. Finally, the gel was washed with acetone, then dried in at $110{ }^{\circ} \mathrm{C}$ for $24 \mathrm{~h}$. The obtained powder was labeled as RHACCl.

\section{lodide-exchanged polymer}

Exchanging chloride ions with iodide ions was carried out in accordance with the procedure described by Ahmed and Parish [28]. RHACCl was suspended within dry acetone containing potassium iodide, and then the mixture was refluxed for $60 \mathrm{~h}$. The obtained solid precipitate was washed with distilled water, methanol and ether and dried at $100{ }^{\circ} \mathrm{C}$. The resultant powder was labeled as RHACI.

\section{Functionalization with ethylenediamine and salicylaldehyde}

A mixture of $1.0 \mathrm{~g}$ of RHAC-I, $16.6 \mathrm{mmol} 0.9 \mathrm{~mL}$ of ethylene diamine and $16.6 \mathrm{mmol} 2.3 \mathrm{~mL}$ of $\mathrm{Et}_{3} \mathrm{~N}$ was refluxed with $30 \mathrm{~mL}$ of toluene at $110^{\circ} \mathrm{C}$ in an oil bath for $12 \mathrm{~h}$. The obtained material was filtered and washed with DCM and DMF, then it was dried in an oven. A beige precipitate of ethylene diamine modified silica was formed, labeled RHACEN. $1.0 \mathrm{~g}$ of the RHACEN was added to excess $\mathrm{mL}$ of salicylaldehyde about 3.0, and the mixture was refluxed in $30 \mathrm{~mL}$ of ethanol at $50{ }^{\circ} \mathrm{C}$ for $6 \mathrm{~h}$. The products were filtered and washed with an amount of ethanol and acetone. The yellow precipitate was collected and labeled as RHACSALEN. Scheme 1 represents the steps followed in the preparation of RHACSALEN ligand.

\section{Metal uptake experiments}

Two hundred and fifty miligrams of RHACSALEN was shaken with $50 \mathrm{~mL}, 0.1 \mathrm{M}$ of aqueous solution of metal(II) ions (Co(II), $\mathrm{Ni}(\mathrm{II}), \mathrm{Cu}(\mathrm{II})$ ) using a plastic container. Measurements of the concentration of metal ions were carried out by withdrawing a sample of $0.5 \mathrm{~mL}$ from the solution using a filtered syringe. Samples were diluted to the linear range of the calibration curve for 

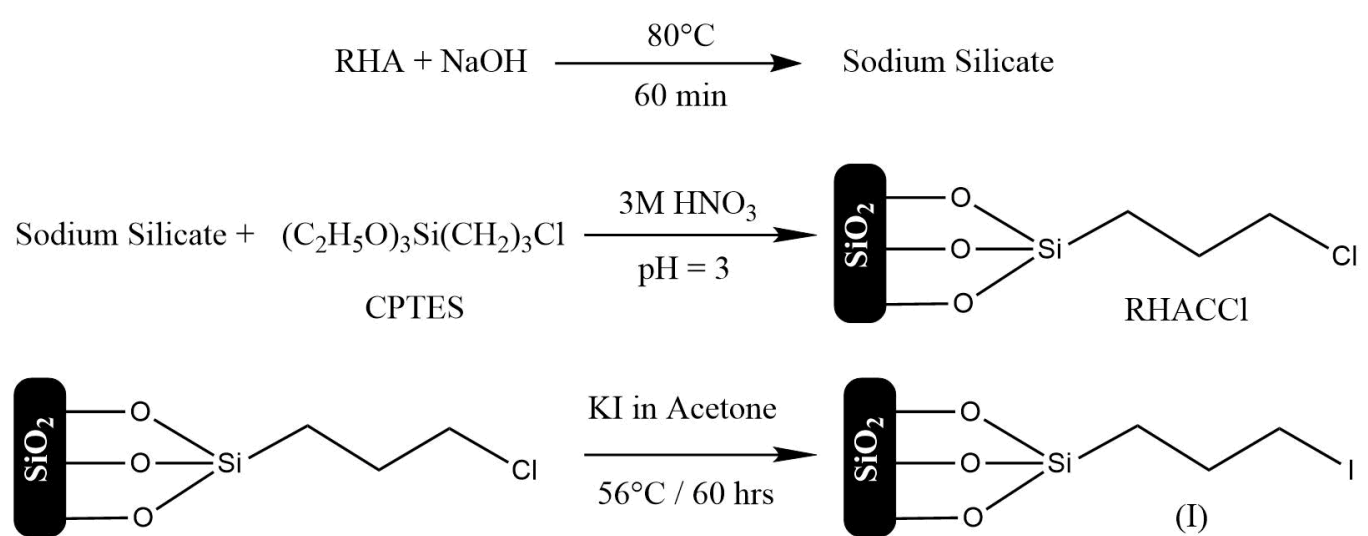

RHACI

(I)

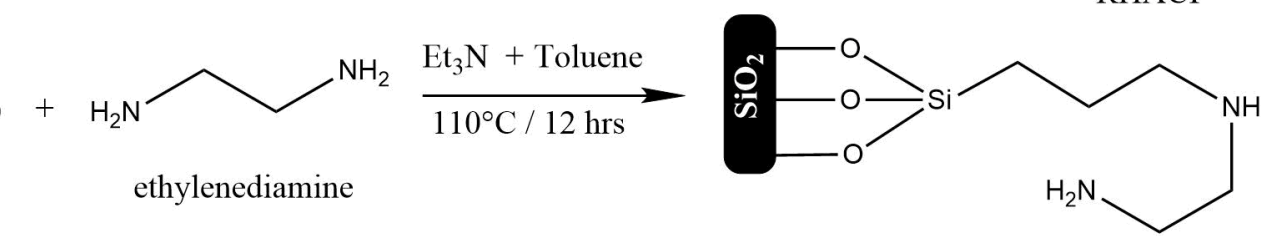

(II)

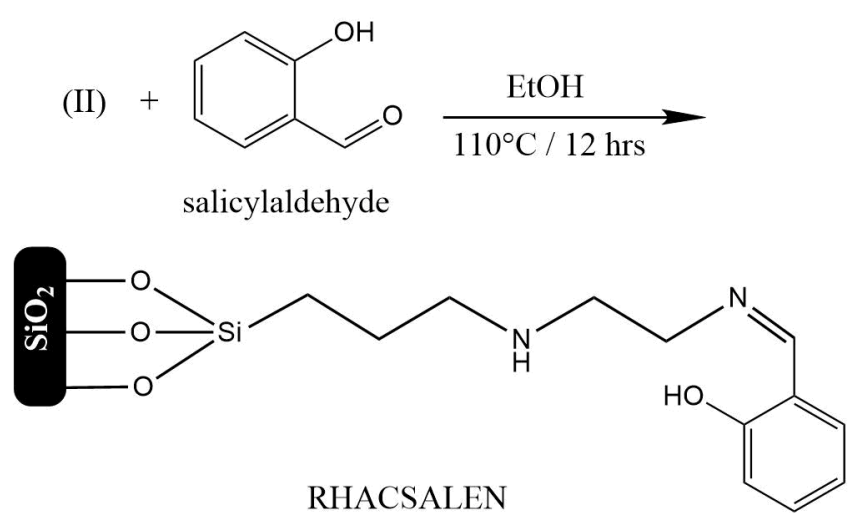

Scheme 1. Synthesis of RHACSALEN ligand

each metal. Metal ion uptake was calculated as mmole of metal per gram of ligand. Time of shaking, the concentration of metal, the mass of the ligand and $\mathrm{pH}$ of the solution were examined.

\section{- RESULTS AND DISCUSSION}

\section{FTIR Spectroscopy Analysis}

Functionalization of the obtained silica was monitored by comparing FTIR spectra of precursor and products. FTIR spectra of RHA, RHACCL, RHACI, RHACEN are presented in Fig. 1 (a-d) and FTIR spectrum of RHACSALEN is presented in Fig. 1(e). The peaks at 1082,796 , and $474 \mathrm{~cm}^{-1}$ are present in all spectra and are attributed to the $\mathrm{Si}-\mathrm{O}-\mathrm{Si}$ group [14]. The broadband that appears between 3200 and $3600 \mathrm{~cm}^{-1}$ is attributed to $\mathrm{O}-\mathrm{H}$ stretching vibration of $\mathrm{Si}-\mathrm{OH}$ groups as well as absorbed water onto the surface of silica. The appearance of the peak at $2951 \mathrm{~cm}^{-1}$, which is attributed to the stretching of the aliphatic $\mathrm{CH}_{2}$ group, is a strong evidence of the successful attachment of CPTES to the prepared silica. The peaks at 3523 and $3446 \mathrm{~cm}^{-1}$ in Fig. 1(d) are attributed to the symmetric and asymmetric stretching of $\mathrm{N}-\mathrm{H}$ bond of the primary amine in RHACEN, while the peaks at 3341 and $1663 \mathrm{~cm}^{-1}$ are attributed respectively to the stretching and bending of $\mathrm{N}-\mathrm{H}$ bond in the secondary amine in the same moiety. The appearance of these peaks is a strong evidence of the successful attachment of ethylenediamine group to RHACI. 


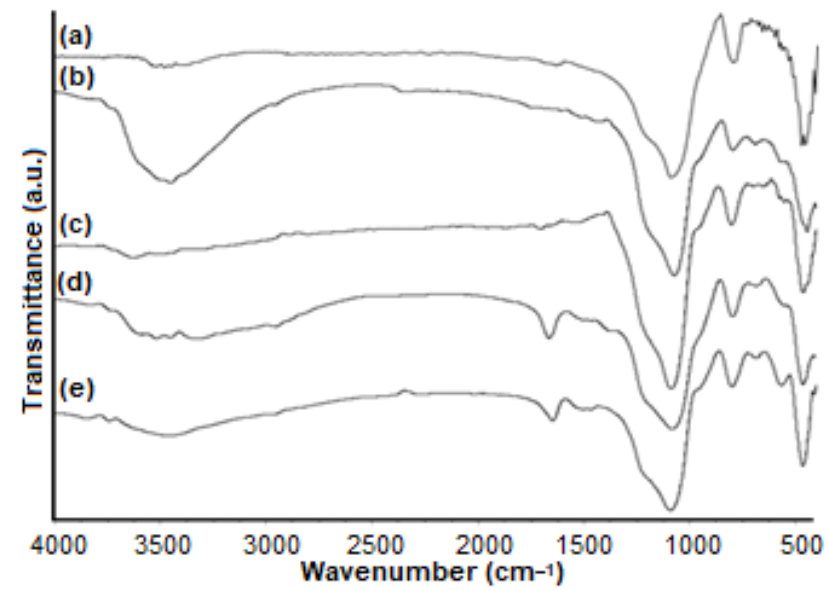

Fig 1. FTIR spectra: (a) RHA, (b) RHACl, (c) RHACI, (d) RHACEN and (e) RHACSALEN

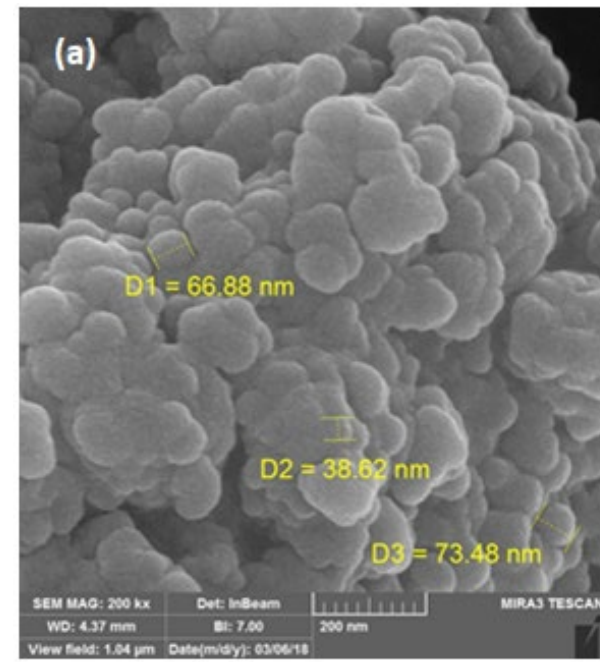

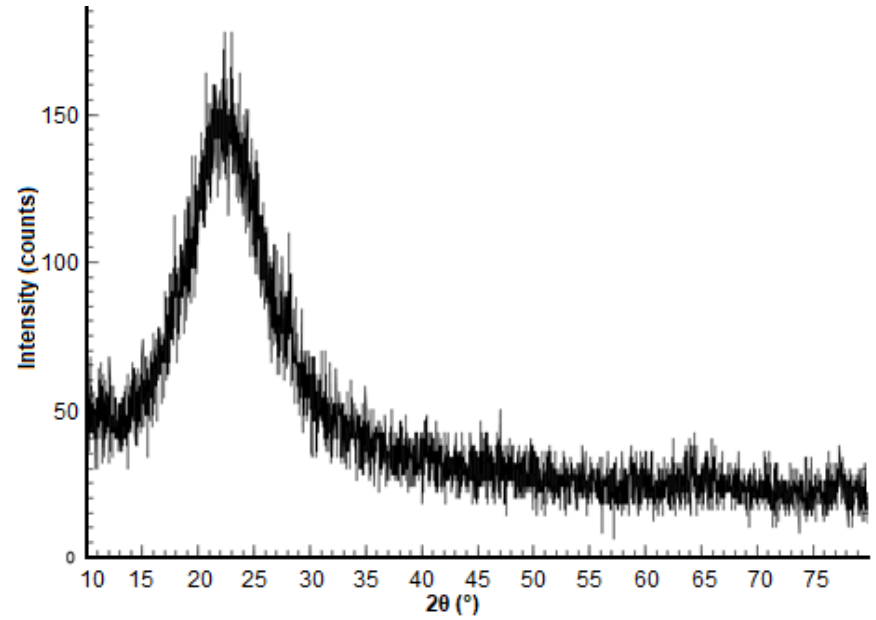

Fig 2. XRD pattern of RHACSALEN

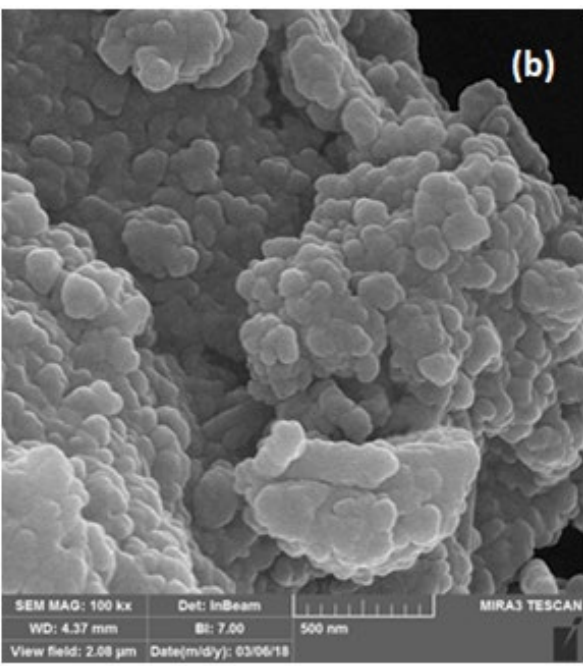

(b)

Fig 3. SEM images of the functionalized silica. (a) $200 \mathrm{~nm}$ (b) $500 \mathrm{~nm}$

It can be seen from Fig. 1(e) that the peaks attributed to the stretching of the $\mathrm{N}-\mathrm{H}$ bond of primary amine are absent in this spectrum. In addition, the peak at $1644 \mathrm{~cm}^{-1}$ refers to the isomethene group $(\mathrm{C}=\mathrm{N})$ [29]. The stretching of aliphatic $\mathrm{CH}_{2}$ for propyl chain appears at $2955 \mathrm{~cm}^{-1}$. This provides strong evidence that the reaction between RHACEN and salicylaldehyde was successful and the Schiff base was formed.

\section{X-ray Diffraction Pattern}

The X-ray diffraction pattern of RHACSALEN is shown in Fig. 2. XRD analysis revealed the occurrence of the broad diffused peak with maximum intensity at $22-23^{\circ}$ (20), though sharp peaks were absent. This result, which is in agreement with a strong broad peak of amorphous silica [30], indicates that the amorphous nature of the functionalized silica was analyzed.

\section{Elemental Analysis CHNS}

Elemental analysis of RHACSALEN showed an increase in the percentages of $\mathrm{C}$ and $\mathrm{H}$ compared with RHA and RHACI [14]. Furthermore, the elemental analysis of RHACSALEN indicated the presence of $\mathrm{N}$ which provides further confirmation of the successful immobilization of the Schiff base onto RHACI. A similar conclusion was drawn by Adam et al. [27] and Mihsen et al. [14]. 


\section{SEM-EDS Analysis}

SEM images of the functionalized silica are shown in Fig. 3. These images show that the particles of the functionalized silica are granular and irregularly shaped with an average diameter of ca. $60 \mathrm{~nm}$.

Fig. 4 shows the spectrum obtained from EDX analysis. This spectrum showed the presence of nitrogen which can be considered further proof for the successful incorporation of salen complex onto the surface of silica. The average value of the chemical composition obtained from EDX analysis is shown in Table 2.

\section{AFM Analysis}

AFM technique was employed to investigate the topography of the prepared ligand surface. The atomic force microscopy (AFM) images and granularity normal distribution of the RHACSALEN are shown in Fig. 5-6. The obtained results revealed that the average roughness of the surface for RHACI was increased upon functionalization process from 6.35 to $11.6 \mathrm{~nm}$. This change may be attributed to the successful modification of the surface of the ligand from RHACI to RHACSALEN. Additionally, AFM results showed that the average diameter of the prepared ligand was $72 \mathrm{~nm}$ which is slightly larger than the result obtained via SEM technique.

\section{Thermal Analysis}

TGA-DTG analysis was performed to determine the thermal stability of the functionalized silica, and the obtained results are depicted in Fig. 7.

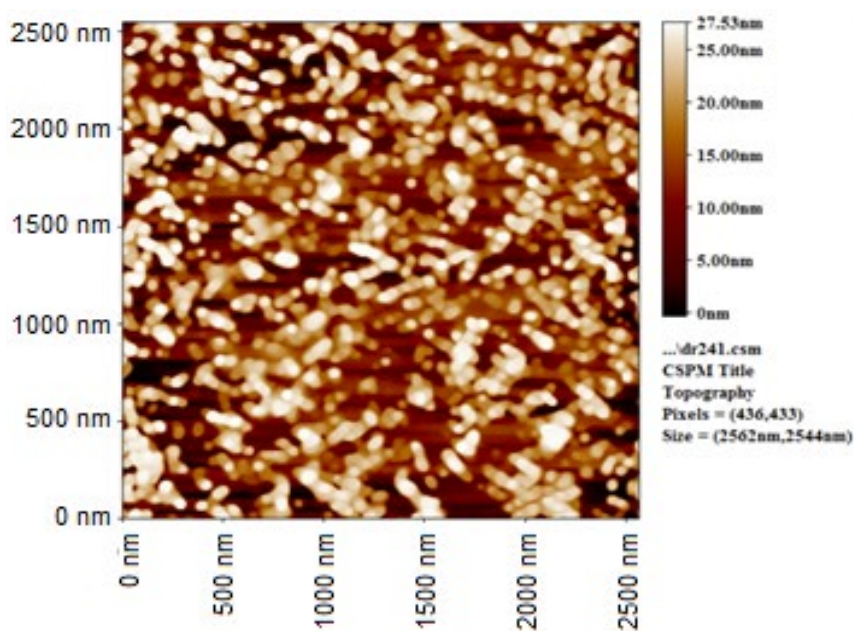

Fig 5. AFM image of RHACI (left); RHACSLAEN (right)
Table 1. Elemental analysis of RHA, RHACI, and RHACSALEN

\begin{tabular}{lcccc}
\hline Sample & $\mathrm{C}(\%)$ & $\mathrm{H}(\%)$ & $\mathrm{N}(\%)$ & $\mathrm{S}(\%)$ \\
\hline RHA & 1.6 & 0.84 & & \\
RHACI & 9.98 & 1.61 & - & - \\
RHACSALEN & 11.57 & 1.95 & 1.90 & - \\
\hline
\end{tabular}

Table 2. The average values obtained from EDX analysis of RHACSALEN

\begin{tabular}{lrr}
\hline Element & \multicolumn{1}{c}{ W\% } & \multicolumn{1}{c}{ A\% } \\
\hline $\mathrm{C}$ & 11.83 & 19.24 \\
$\mathrm{~N}$ & 0.89 & 1.25 \\
$\mathrm{O}$ & 36.52 & 44.59 \\
$\mathrm{Si}$ & 48.05 & 33.42 \\
$\mathrm{~S}$ & 0.21 & 0.13 \\
$\mathrm{Cl}$ & 2.49 & 1.37 \\
$\mathrm{I}$ & 0.01 & 0.01 \\
\hline & 100 & \multicolumn{1}{c}{100} \\
\hline
\end{tabular}



Fig 4. EDX chart for RHACSALEN

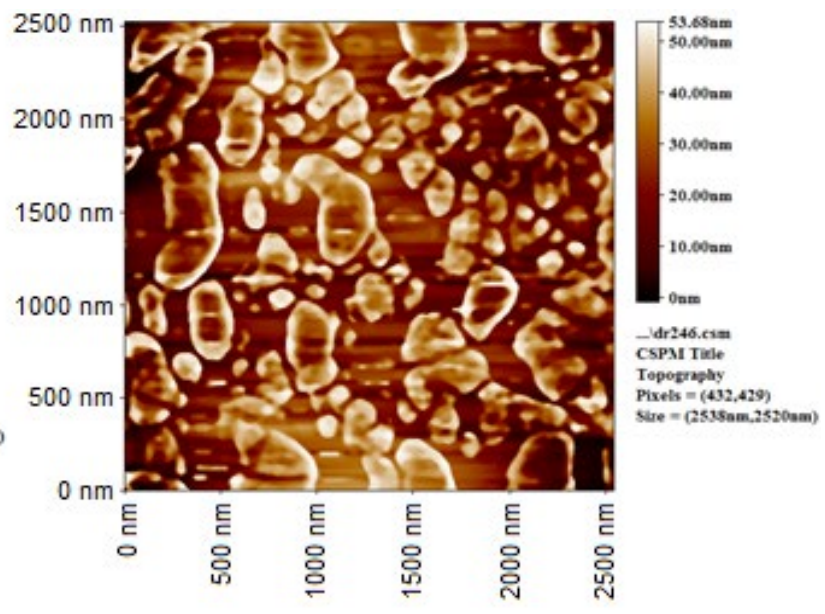



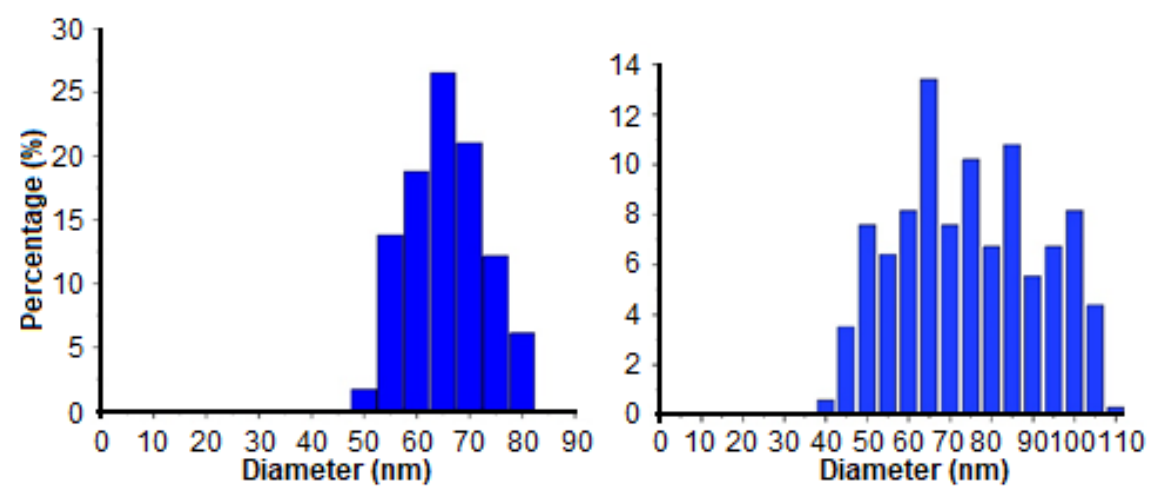

Fig 6. The granularity cumulation distribution of RHACI (left); RHACSLAEN (right)

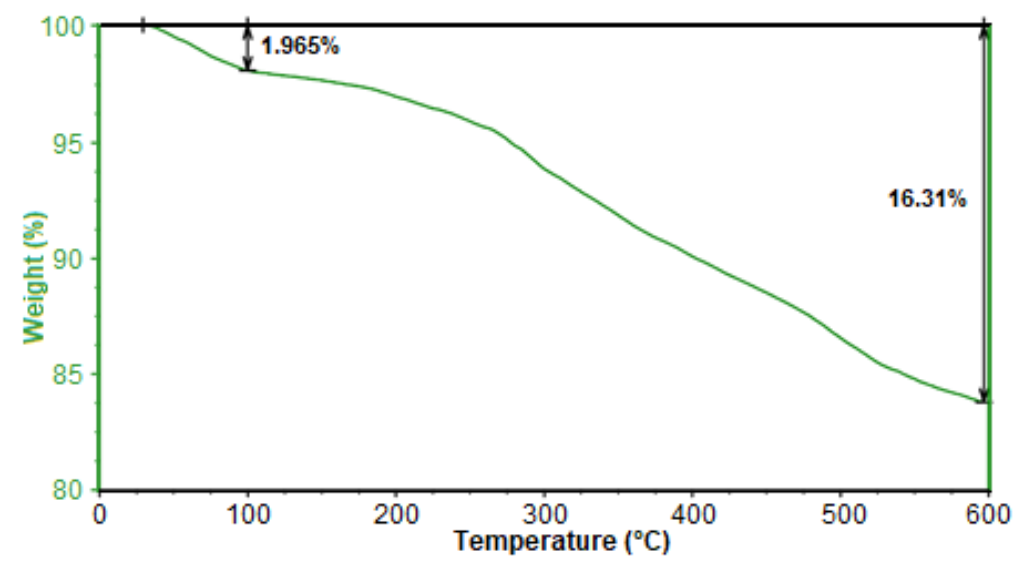

Fig 7. TGA plot of RHACSALEN

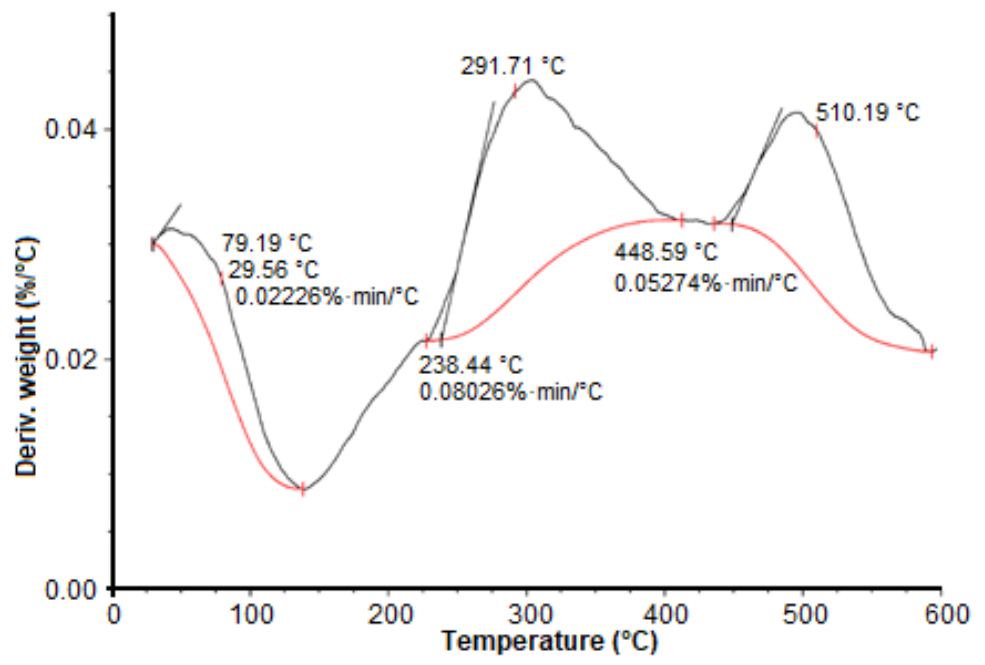

Fig 8. DTG plot of RHACSALEN

The results showed that the functionalized silica exhibited two characteristic weight loss stages. Initially, weight loss occurred between 25 and $120^{\circ} \mathrm{C}$ with about 2 wt.\% loss. This was attributed to the evaporation of water molecules adsorbed on the surface of silica [14,31]. The second weight loss happened between 250 and $600^{\circ} \mathrm{C}$ with about 16 wt.\% loss, which may be ascribed to dihydroxylation and loss of water or alcohol from silica [32-33].

Fig. 8 shows the result of DTG analysis for RHACSALEN. It reveals two major weight loss steps which are in agreement with the results obtained from 


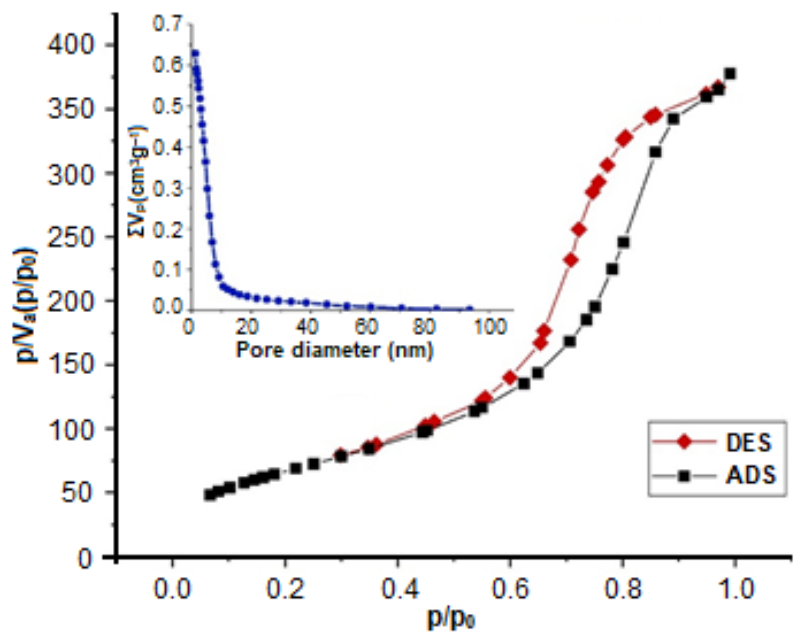

Fig 9. Adsorption/desorption isotherm of the functionalized silica. Inset: The pore size distribution

TGA analysis about the evaporation of water molecules and the dihydroxylation and loss of water and alcohol from silica [34].

\section{Nitrogen Adsorption Desorption Analysis}

The surface area of the functionalized silica was investigated employing nitrogen adsorption-desorption. Fig. 9 shows the obtained isotherm. The pore size distribution graph is inset. According to the IUPAC classification of hysteresis loops, this isotherm follows type IV and $\mathrm{H} 2$ isotherms [35]. It can be seen in Fig. 9 that $\mathrm{N}_{2}$ adsorption isotherm of the functionalized silica gave a hysteresis loop observed in the range of $\mathrm{p} / \mathrm{p}_{0}$ values between 0.6 and 0.9 , which is associated with capillary condensation, a characteristic of mesoporous materials [11].

A specific area, pore size and pore volume of the functionalized silica was obtained employing BET analysis, and it was found to be equal to $247.55 \mathrm{~m}^{2} / \mathrm{g}$, $0.582 \mathrm{~cm}^{3} / \mathrm{g}$, and $9.41 \mathrm{~nm}$ respectively.

\section{Metal Uptake Experiments}

\section{Effect of shaking time on the metal uptake}

In order to determine the effect of shaking time on the metal uptake, $0.25 \mathrm{~g}$ of the ligand was shaken with an aqueous solution of divalent metal ions for $24 \mathrm{~h}$. The results, depicted in Fig. 10, shows an increase in the uptake of the metal ions as a function to the time of exposure in a nonlinear fashion. Metal ion uptake

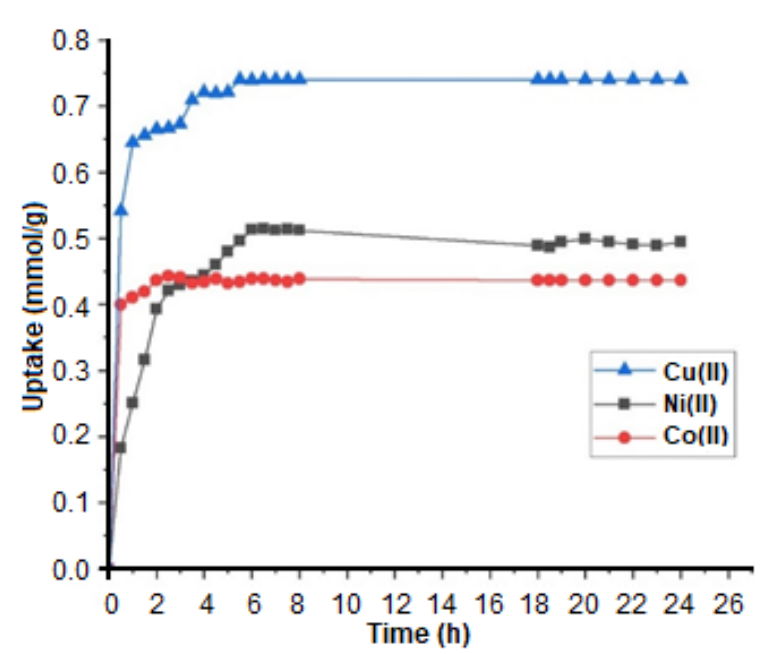

Fig 10. The uptake of $\mathrm{Co}(\mathrm{II}), \mathrm{Ni}(\mathrm{II})$ and $\mathrm{Cu}(\mathrm{II})$ ions by RHACSALEN versus time

increased rapidly at the beginning then it became slower as the time progressed, with the exception of the case of $\mathrm{Ni}(\mathrm{II})$ ions which showed an increase in metal uptake capacity after reaching its maximum. The increase in metal uptake capacity may be ascribed to diffusion factors, as the already complexed groups prevent metal ions from contacting unreacted ligand groups. These results are in line with other works [12]. Saturation occurred after $3 \mathrm{~h}$ in case of cobalt, while in case of nickel and copper saturation occurred after $6 \mathrm{~h}$.

First order (Eq. (1)), second order (Eq. (2)) [25], pseudo-first order (Eq. (3)) and pseudo-second-order (Eq. (4)) [36] were employed to evaluate the experimental data in order to determine the adsorption kinetics.

Kinetic model and parameters for $\mathrm{Ni}(\mathrm{II}), \mathrm{Cu}(\mathrm{II})$ and $\mathrm{Co}(\mathrm{II})$ are presented in Table 3.

$\ln C_{e}=-k_{1} t+\ln C_{0}$

$\frac{1}{\mathrm{C}_{\mathrm{e}}}=\mathrm{k}_{2} \mathrm{t}+\frac{1}{\mathrm{C}_{0}}$

$\log \left(1-\frac{\mathrm{q}_{\mathrm{t}}}{\mathrm{q}_{\mathrm{e}}}\right)=-\frac{\mathrm{k}_{3}}{2.303} \mathrm{t}$

$\frac{\mathrm{t}}{\mathrm{q}_{\mathrm{t}}}=\frac{1}{\mathrm{k}_{4} \mathrm{q}_{\mathrm{e}}^{2}}+\frac{1}{\mathrm{q}_{\mathrm{e}}} \mathrm{t}$

where $\mathrm{C}_{e}$ is the concentration of metal ion at equilibrium $(\mathrm{mM}), \mathrm{C}_{0}$ is the initial concentration of metal ion $(\mathrm{mM})$; $\mathrm{q}_{\mathrm{e}}$ and $\mathrm{q}_{\mathrm{t}}$ are the amounts of metal ions adsorbed $\left(\mathrm{mol} \mathrm{g}^{-1}\right)$ at equilibrium and at any time $\mathrm{t}\left(\mathrm{mmol} \mathrm{g}^{-1}\right)$, respectively; 
$\mathrm{k}_{1}, \mathrm{k}_{2}, \mathrm{k}_{3}$ and $\mathrm{k}_{4}$ are adsorption rate constant of first order $\left(\min ^{-1}\right)$, second order $\left(\mathrm{mM}^{-1} \mathrm{~min}^{-1}\right)$, pseudo-first order $\left(\mathrm{min}^{-1}\right)$ and pseudo-second-order $\left(\mathrm{g} \mathrm{mmol}{ }^{-1} \mathrm{~min}^{-1}\right)$, respectively.

The obtained results show that the pseudo-secondorder model has the highest correlation coefficient for $\mathrm{Ni}(\mathrm{II}), \mathrm{Cu}(\mathrm{II})$ and $\mathrm{Co}(\mathrm{II})$. Additionally, the value of $\mathrm{q}_{\mathrm{e}}$ calculated from the pseudo-second-order as $(21.23 \mathrm{mmol}$ $\mathrm{g}^{-1}$ for $\mathrm{Ni}(\mathrm{II}), 22.13 \mathrm{mmol} \mathrm{g}^{-1}$ for $\mathrm{Cu}(\mathrm{II}), 17.53$ for $\mathrm{Co}(\mathrm{II})$ ) is close to the experimental $\mathrm{q}_{\mathrm{e}}$ as $\left(22.47 \mathrm{mmol} \mathrm{g}^{-1}\right.$ for $\mathrm{Ni}(\mathrm{II}), 23.8 \mathrm{mmol} \mathrm{g}^{-1}$ for $\mathrm{Cu}(\mathrm{II}), 18.21 \mathrm{mmol} \mathrm{g}^{-1}$ for $\mathrm{Co}(\mathrm{II}))$ in comparison with the experimental $\mathrm{q}_{\mathrm{e}}$ obtained from the pseudo-first-order model as $\left(11.67 \mathrm{mmol} \mathrm{g}^{-1}\right.$ for $\mathrm{Ni}(\mathrm{II}), 7.93 \mathrm{mmol} \mathrm{g}^{-1}$ for $\mathrm{Cu}(\mathrm{II}), 8.11 \mathrm{mmol} \mathrm{g}^{-1}$ for $\mathrm{Co}(\mathrm{II})$ ). These results indicate that the applicability of pseudosecond-order model is a better option to describe the adsorption of $\mathrm{Ni}(\mathrm{II}), \mathrm{Cu}(\mathrm{II})$ and $\mathrm{Co}(\mathrm{II})$ ions onto RHACSALEN. Consequently, the kinetic does not involve a mass transfer in solution and the adsorption is chemical [25].

\section{Effect of the initial concentration of metal ion solution}

The effect of the initial concentration of the metal
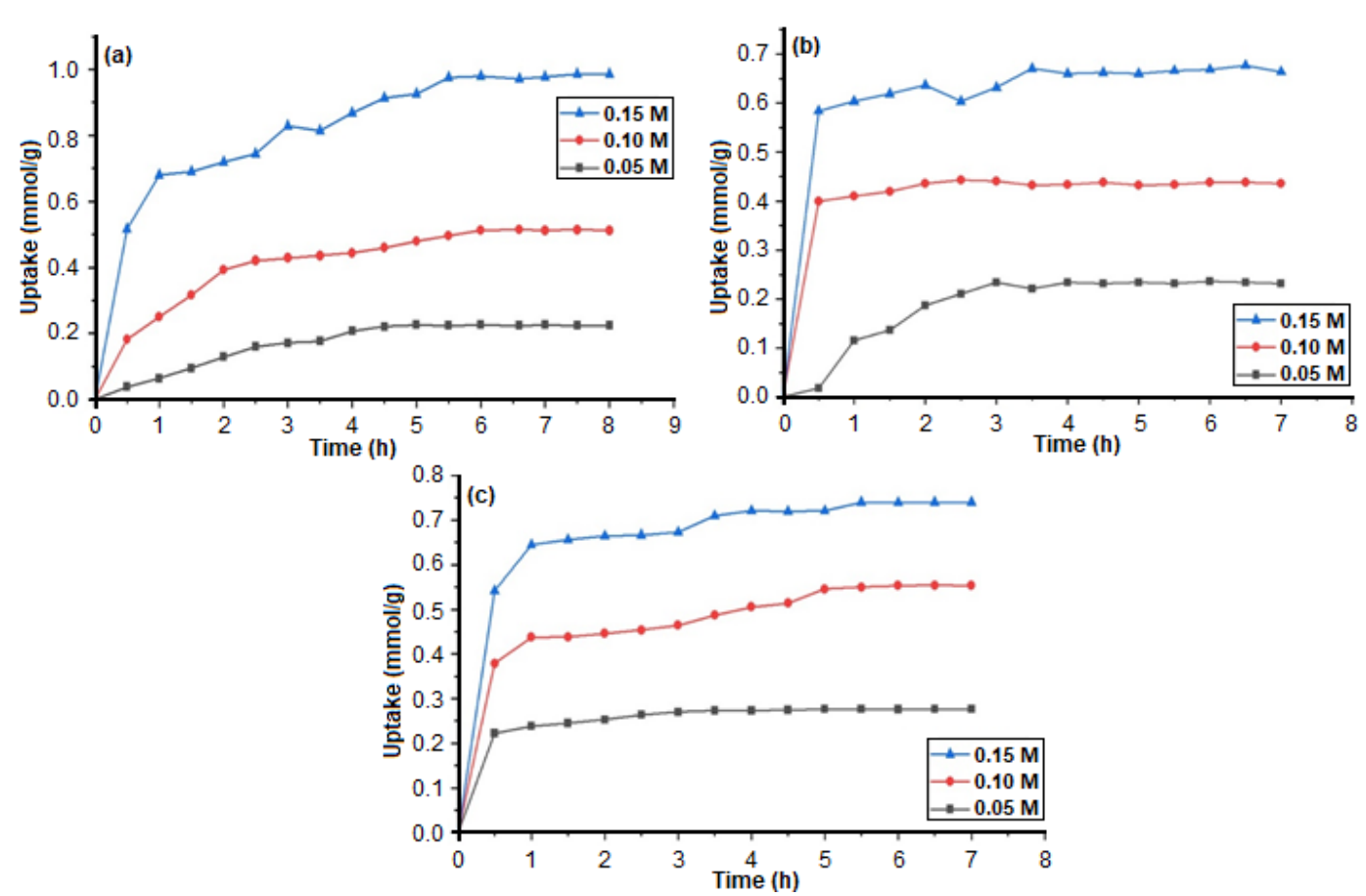

Fig 11. The uptake of (a) $\mathrm{Ni}(\mathrm{II})$ ions, (b) $\mathrm{Co}(\mathrm{II})$ ions, and (c) $\mathrm{Cu}$ (II) ions by RHACSALEN versus different initial concentrations of metal ion solution

ion solution was investigated. $0.25 \mathrm{~g}$ of RHACSALEN was shaken for $8 \mathrm{~h}$ with three solutions of metal ion where each of the solution has different initial concentration. The results, expressed in Fig. 11(a-c), show

Table 3. Rate constant of $\mathrm{Ni}(\mathrm{II}), \mathrm{Cu}(\mathrm{II})$ and $\mathrm{Co}(\mathrm{II})$ adsorption on RHACSALEN and the linear coefficient in various kinetics models

\begin{tabular}{lll}
\hline Kinetic model & Rate constant & $\mathrm{R}^{2}$ \\
\hline $\mathrm{Ni}(\mathrm{II})$ & & \\
\hline First order & $0.0999 \mathrm{~min}^{-1}$ & 0.8536 \\
Second order & $1.5354 \mathrm{mM}^{-1} \mathrm{~min}^{-1}$ & 0.9104 \\
Pseudo-first order & $0.4629 \mathrm{~min}^{-1}$ & 0.9434 \\
Pseudo-second order & $0.0603 \mathrm{mM}^{-1} \mathrm{~min}^{-1}$ & 0.9942 \\
\hline $\mathrm{Cu}(\mathrm{II})$ & & \\
\hline First order & $0.0511 \mathrm{~min}^{-1}$ & 0.9477 \\
Second order & $1.0047 \mathrm{mM}^{-1} \mathrm{~min}^{-1}$ & 0.9521 \\
Pseudo-first order & $0.3977 \mathrm{~min}^{-1}$ & 0.9220 \\
Pseudo-second order & $0.0731 \mathrm{mM}^{-1} \mathrm{~min}^{-1}$ & 0.9932 \\
\hline Co(II) & & \\
\hline First order & $0.0316 \mathrm{~min}^{-1}$ & 0.9226 \\
Second order & $0.5483 \mathrm{mM}^{-1} \mathrm{~min}^{-1}$ & 0.9230 \\
Pseudo-first order & $0.2716 \mathrm{~min}^{-1}$ & 0.9142 \\
Pseudo-second order & $0.579 \mathrm{mM}^{-1} \mathrm{~min}^{-1}$ & 0.9949 \\
\hline
\end{tabular}


Table 4. Langmuir and Freundlich parameters for $\mathrm{Ni}(\mathrm{II}), \mathrm{Cu}(\mathrm{II})$ and $\mathrm{Co}(\mathrm{II})$ adsorption

\begin{tabular}{lllllll}
\hline & \multicolumn{3}{c}{ Langmuir parameters } & \multicolumn{4}{c}{ Freundlich parameters } \\
\cline { 2 - 7 } & $\mathrm{R}^{2}$ & $\mathrm{qm}$ & $\mathrm{b}$ & $\mathrm{R}^{2}$ & $\mathrm{Kf}$ & $\mathrm{n}$ \\
\hline $\mathrm{Ni}(\mathrm{II})$ & 0.932 & $57.4 \mathrm{mg} / \mathrm{g}$ & 10.69 & 0.990 & 0.293 & 1.13 \\
$\mathrm{Cu}(\mathrm{II})$ & 0.863 & $90.2 \mathrm{mg} / \mathrm{g}$ & 6.624 & 0.979 & 0.247 & 1.24 \\
$\mathrm{Co}(\mathrm{II})$ & 0.937 & $83.72 \mathrm{mg} / \mathrm{g}$ & 6.299 & 0.997 & 0.588 & 1.0 \\
\hline
\end{tabular}

Table 5. Comparison of maximum capacity $\mathrm{q}_{\mathrm{m}}(\mathrm{mg} / \mathrm{g})$ for $\mathrm{Ni}(\mathrm{II}), \mathrm{Cu}(\mathrm{II})$ and $\mathrm{Cu}(\mathrm{II})$ adsorption by variously reported adsorbents

\begin{tabular}{lllll}
\hline No & Adsorbent & Metal-ion & $\mathrm{q}_{\mathrm{m}}(\mathrm{mg} / \mathrm{g})$ & Ref \\
\hline \multirow{2}{*}{ S } & Surface modified Strychnos potatorum & $\mathrm{Ni}(\mathrm{II})$ & 74.55 & {$[37]$} \\
& seeds & & & \\
\hline 2 & Modified magnetic chitosan chelating & $\mathrm{Ni}(\mathrm{II})$, & 40.15, & {$[38]$} \\
& resin & $\mathrm{Cu}(\mathrm{II})$, & 103.16, & \\
& & $\mathrm{Co}(\mathrm{II})$ & 53.51 & \\
\hline 3 & Phosphonate modified silica & $\mathrm{Ni}(\mathrm{II})$, & 12.47, & {$[39]$} \\
& & $\mathrm{Cu}(\mathrm{II})$, & 21.02, & \\
& & $\mathrm{Co}(\mathrm{II})$ & 7.43 & \\
\hline 4 & Xanthate-modified chitosan/poly(N- & $\mathrm{Ni}(\mathrm{II})$, & 71.8, & {$[40]$} \\
& isopropylacrylamide) composite hydrogel & $\mathrm{Cu}(\mathrm{II})$ & 125.3 & \\
\hline 5 & Salen-modified silica (RACSALEN) & $\mathrm{Ni}(\mathrm{II})$, & 57.4, & This \\
& & $\mathrm{Cu}(\mathrm{II})$, & 90.2, & work \\
& & $\mathrm{Co}(\mathrm{II})$ & 83.72 & \\
\hline
\end{tabular}

that the uptake capacity increases as the initial concentration of metal ion solution increases. As the initial concentration of the metal ions increased from 0.05 to $0.15 \mathrm{M}$, the uptake of $\mathrm{Ni}(\mathrm{II}), \mathrm{Cu}(\mathrm{II})$ and $\mathrm{Co}(\mathrm{II})$ ions increased from 0.20 to $0.90,0.20$ to 0.65 and 0.23 to $0.70 \mathrm{mmol} \mathrm{metal}(\mathrm{II}) / \mathrm{g}$ ligand respectively.

The obtained data were fitted to Langmuir and Freundlich two-parameters isotherm models. The linear shape of the Langmuir model is described as follows [36]:

$\frac{\mathrm{C}_{\mathrm{e}}}{\mathrm{q}_{\mathrm{e}}}=\frac{\mathrm{C}_{\mathrm{e}}}{\mathrm{q}_{\mathrm{m}}}+\frac{1}{\mathrm{q}_{\mathrm{m}} \mathrm{b}}$

where $\mathrm{q}_{\mathrm{e}}$ is the equilibrium amount of adsorbate $(\mathrm{mg} / \mathrm{g})$, $\mathrm{C}_{\mathrm{e}}$ is the equilibrium concentration of adsorbate $(\mathrm{mg} / \mathrm{L})$, $\mathrm{q}_{\mathrm{m}}$ is the maximum adsorption capacity and $\mathrm{b}$ is the Langmuir constant.

Freundlich model is described as follows:

$\ln \mathrm{q}_{\mathrm{e}}=\ln \mathrm{K}_{\mathrm{f}}+\frac{1}{\mathrm{n}} \ln \mathrm{C}_{\mathrm{e}}$

where $\mathrm{q}_{e}$ is the amount of adsorbate $(\mathrm{mg} / \mathrm{g}), \mathrm{C}_{e}$ is the equilibrium concentration of adsorbate $(\mathrm{mg} / \mathrm{L}), \mathrm{K}_{\mathrm{f}}$ and $1 / \mathrm{n}$ are the Freundlich constants.
The relationship between the Langmuir and Freundlich parameters with correlation coefficient was shown in Table $4 . \mathrm{R}^{2}$ values suggest that the adsorption isotherm data were best fitted to the Freundlich adsorption isotherm model. These results suggest that the adsorption of $\mathrm{Ni}(\mathrm{II}), \mathrm{Cu}(\mathrm{II})$ and $\mathrm{Cu}(\mathrm{II})$ onto RHACSLAEN was in multilayer fashion [37].

The comparison of maximum capacity for $\mathrm{Ni}(\mathrm{II})$, $\mathrm{Cu}(\mathrm{II})$ and $\mathrm{Cu}(\mathrm{II})$ adsorption by variously reported adsorbents is given in Table 5.

\section{Effect of the mass of the functionalized silica}

The effect of the mass of the functionalized silica was investigated using three different masses of ligand (100, 150, and $250 \mathrm{mg}$ ). Fig. 12(a-c) illustrate the uptake capacity of RHACSALEN for $\mathrm{Ni}(\mathrm{II}), \mathrm{Co}(\mathrm{II})$ and $\mathrm{Cu}(\mathrm{II})$ ions respectively. The obtained results showed that the maximum uptake capacity increased as the mass of the ligand increased for both of $\mathrm{Ni}$ (II) and $\mathrm{Co}$ (II) ions (0.9 and $0.65 \mathrm{mmol} \mathrm{metal(II)/g} \mathrm{ligand} \mathrm{respectively),} \mathrm{however}$ in the case of $\mathrm{Cu}$ (II) ions the maximum uptake capacity 

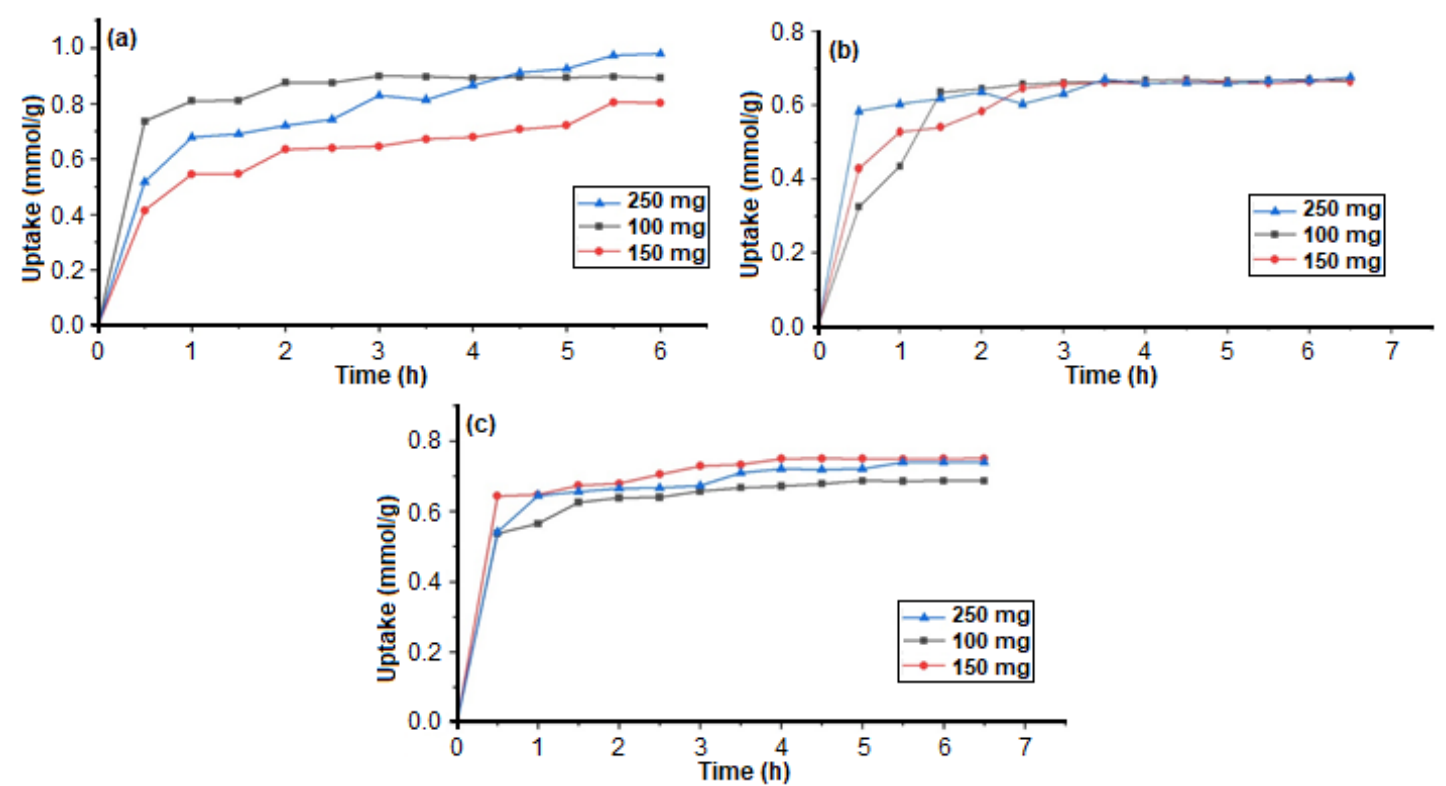

Fig 12. The uptake of (a) Ni(II) ions, (b) Co(II) ions, and (c) Cu(II) ions by RHACSALEN versus different masses of the ligand
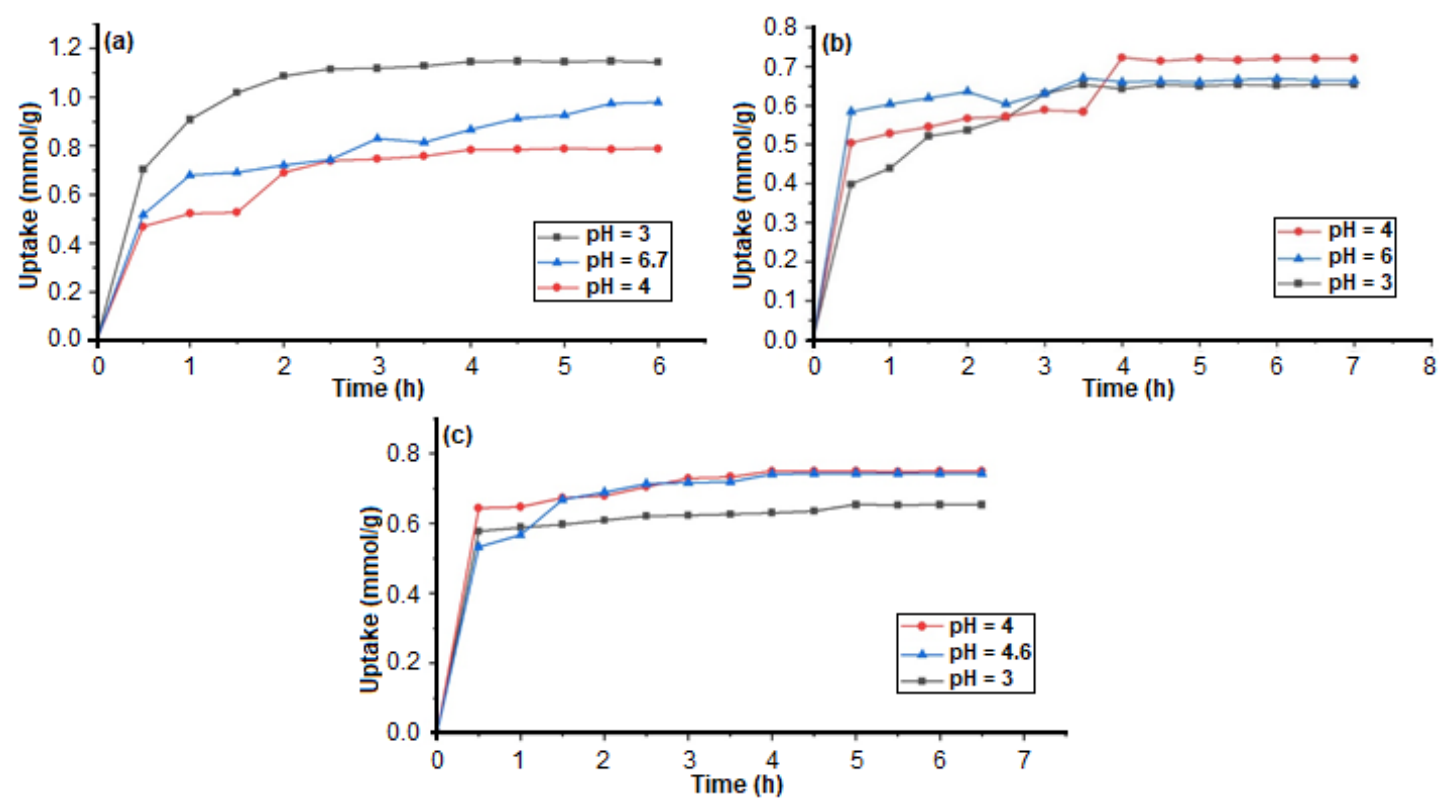

Fig 13. The uptake of (a) $\mathrm{Ni}(\mathrm{II})$ ions, (b) $\mathrm{Co}(\mathrm{II})$ ions, and (c) $\mathrm{Cu}$ (II) ions by RHACSALEN versus different initial $\mathrm{pH}$ values of metal ion solution

was very close in both 150 and $250 \mathrm{mg}$ of the ligand. These results can be rationalized on the basis that as the amount of the ligand increases, more ligand site is accessible for complexation with metal ions.

\section{Effect of $\mathrm{pH}$}

The effect of $\mathrm{pH}$ of the metal ion solution on the preconcentration process was studied by exposing the functionalized silica to solutions of metal ions at three different $\mathrm{pH}$ values. The results, expressed in Fig. 13(ac), show that metal uptake capacity increased as the $\mathrm{pH}$ decreased and reached its maximum at $\mathrm{pH}=3$ in the case of $\mathrm{Ni}$ and $\mathrm{pH}=4$ in the case of $\mathrm{Co}$ and $\mathrm{Cu}$. The decreasing of $\mathrm{pH}$ can be due to ionization of hydrogen of the hydroxyl group in salen moiety and coordinate 
oxygen atom with metal ions. It was noted that the uptake capacity of the ligand declined as the $\mathrm{pH}$ of the solution increased. This behavior is ascribed to the formation of metal hydroxides [9].

\section{- CONCLUSION}

Silica derivative-salen ligand was synthesized and used to extract divalent metal ions ( $\mathrm{Ni}(\mathrm{II}), \mathrm{Co}(\mathrm{II})$ and $\mathrm{Cu}(\mathrm{II}))$ from aqueous solutions. The techniques of characterization proved the successful synthesis of RHACSALEN. FTIR spectra showed the formation of the $\mathrm{C}=\mathrm{N}$ bond. Nitrogen adsorption-desorption analysis stated that RHACSLAEN has a high surface area $247.55 \mathrm{~m}^{2} / \mathrm{g}$. AFM and SEM analysis showed that the average diameter for the prepared ligand particles ranges between 63 and $72 \mathrm{~nm}$. The prepared ligand is very efficient in the removal of metal ions from aqueous solutions, and such a material can be used in numerous applications not only for separation and removal of contaminants but also many other purposes such as catalysts for most organic reactions.

\section{- ACKNOWLEDGMENTS}

The authors are thankful to the University of Kerbala, Ministry of Higher Education and Scientific Research, Republic of Iraq, for supporting this work.

\section{- REFERENCES}

[1] Bose, S., Ganayee, M.A., Mondal, B., Baidya, A., Chennu, S., Mohanty, J.S., and Pradeep, T., 2018, Synthesis of silicon nanoparticles from rice husk and their use as sustainable fluorophores for white light emission, ACS Sustainable Chem. Eng., 6 (5), 62036210.

[2] Shen, Y., 2017, Rice husk silica derived nanomaterials for sustainable applications, Renewable Sustainable Energy Rev., 80, 453-466.

[3] Inba, P.J.K., Annaraj, B., Thalamuthu, S., and Neelakantan, M.A., 2013, Cu(II), Ni(II), and Zn(II) complexes of salan-type ligand containing ester groups: Synthesis, characterization, electrochemical properties, and in vitro biological activities, Bioinorg. Chem. Appl., 2013, 439848.

[4] Tahmasbi, L., Sedaghat, T., Motamedi, H., and Kooti,
M., 2018, Mesoporous silica nanoparticles supported copper(II) and nickel(II) Schiff base complexes: Synthesis, characterization, antibacterial activity and enzyme immobilization, J. Solid State Chem., 258, 517-525.

[5] El-Kurd, H.M., El-Nahhal, I.M., and El-Ashgar, N.M., 2005, Synthesis of new polysiloxaneimmobilized ligand system di(amidomethyl)amine tetraacetic acid, Phosphorus Sulfur Silicon Relat. Elem., 180 (7), 1657-1671.

[6] El-Nahhal, I.M., and El-Ashgar, N.M., 2007, A review on polysiloxane-immobilized ligand systems: Synthesis, characterization and applications, J. Organomet. Chem., 692 (14), 2861-2886.

[7] El-Ashgar, N.M., El-Nahhal, I.M., Chehimi, M.M., Babonneau, F., and Livage, J., 2010, Extraction of $\mathrm{Co}, \mathrm{Ni}, \mathrm{Cu}, \mathrm{Zn}$ and $\mathrm{Cd}$ ions using 2aminophenylaminopropylpolysiloxane, Environ. Chem. Lett., 8 (4), 311-316.

[8] El-Nahhal, I.M., El-Shetary, B.A., Salib, K.A.R., ElAshgar, N.M., and El-Hashash, A.M., 2001, Uptake of divalent metal ions $\left(\mathrm{Cu}^{2+}, \mathrm{Ni}^{2+}\right.$, and $\left.\mathrm{Co}^{2+}\right)$ by polysiloxane immobilized triamine-thiol and thiolacetate ligand system, Anal. Lett., 34 (12), 21892202.

[9] Hao, S., Verlotta, A., Aprea, P., Pepe, F., Caputo, D., and $\mathrm{Zhu}, \mathrm{W}$., 2016, Optimal synthesis of aminofunctionalized mesoporous silicas for the adsorption of heavy metal ions, Microporous Mesoporous Mater., 236, 250-259.

[10] Ezzeddine, Z., Batonneau-Gener, I., Pouilloux, Y., Hamad, H., Saad, Z., and Kazpard, V., 2015, Divalent heavy metals adsorption onto different types of EDTA-modified mesoporous materials: Effectiveness and complexation rate, Microporous Mesoporous Mater., 212, 125-136.

[11] Das, T., Roy, A., Uyama, H., Roy, P., and Nandi, M., 2017, 2-Hydroxy-naphthyl functionalized mesoporous silica for fluorescence sensing and removal of aluminum ions, Dalton Trans., 46 (22), 7317-7326.

[12] El-Nahhal, I.M., Zaggout, F.R., and El-Ashgar, N.M., 2000, Uptake of divalent metal ions (Cu, Zn 
and $\mathrm{Cd}$ ) by polysiloxane immobilized monoamine ligand system, Anal. Lett., 33 (10), 2031-2053.

[13] Chen, L., Li, B.D., Xu, Q.X., and Liu, D.B., 2013, A silica gel supported cobalt(II) Schiff base complex as efficient and recyclable heterogeneous catalyst for the selective aerobic oxidation of alkyl aromatics, Chin. Chem. Lett., 24 (9), 849-852.

[14] Mihsen, H., and Sobh, H., 2018, Preparation and characterization of thiourea-silica hybrid as heterogenous catalyst, Asian J. Chem., 30 (5), 937-943.

[15] Das, D.D., and Sayari, A., 2007, Applications of poreexpanded mesoporous silica 6. Novel synthesis of monodispersed supported palladium nanoparticles and their catalytic activity for Suzuki reaction, $J$. Catal., 246 (1), 60-65.

[16] Das, D.D., and Sayari, A., 2007, Amine grafted poreexpanded MCM-41 as base catalysts, Stud. Surf. Sci. Catal., 170, 1197-1204.

[17] Chen, H., Wang, W., Martin, J.C., Oliphant, A.J., Doerr, P.A., Xu, J.F., DeBorn, K.M., Chen, C., and Sun, L., 2013, Extraction of lignocellulose and synthesis of porous silica nanoparticles from rice husks: A comprehensive utilization of rice husk biomass, ACS Sustainable Chem. Eng., 1 (2), 254-259.

[18] Govindarao, V.M.H., 1980, Utilization of rice husk-a preliminary-analysis, J. Sci. Ind. Res., 39 (9), 495-515.

[19] Carmona, V.B., Oliveira, R.M., Silva, W.T.L., Mattoso, L.H.C., and Marconcini, J.M., 2013, Nanosilica from rice husk: Extraction and characterization, Ind. Crops Prod., 43 (1), 291-296.

[20] Leyden, D.E., and Luttrell, G.H., 1975, Preconcentration of trace metals using chelating groups immobilized via silylation, Anal. Chem., 47 (9), 1612-1617.

[21] Leyden, D.E., Steele, M.L., Jablonski, B.B., and Somoano, R.B., 1978, Structural studies of immobilized ethylenediamine as a preconcentrating agent for molybdate and tungstate, Anal. Chim. Acta, 100, 545-554.

[22] El-Nahhal, I.M., Chehimi, M., and Selmane, M., 2017, Synthesis and structural characterization of GSBA-IDA, G-SBA-EDTA and G-SBA-DTPA modified mesoporous SBA-15 silica and their application for removal of toxic metal ions pollutants, Silicon, 10 (3), 981-993.

[23] El-Ashgar, N.M., Silmi, M.K., El-Nahhal, I.M., Chehimi, M.M., and Babonneau, F., 2015, Template synthesis of iminodiacetic acid polysiloxane immobilized ligand systems and their metal uptake capacity, Silicon, 9 (4), 563-575.

[24] El-Ashgar, N.M., El-Nahhal, I.M., Chehimi, M.M., Babonneau, F., and Livage, J., 2012, Synthesis of polysiloxane-immobilized monoamine, diamine, and triamine ligand systems in the presence of CTAB and their applications, Phosphorus Sulfur Silicon Relat. Elem., 187 (3), 392-402.

[25] Hastuti, S., Nuryono, and Kuncaka, A., 2015, Larginine-modified silica for adsorption of gold(III), Indones. J. Chem., 15 (2), 108-115.

[26] Ahmed, A.E., and Adam, F., 2007, Indium incorporated silica from rice husk and its catalytic activity, Microporous Mesoporous Mater., 103 (1-3), 284-295.

[27] Adam, F., Osman, H., and Hello, K.M., 2009, The immobilization of 3-(chloropropyl)triethoxysilane onto silica by a simple one-pot synthesis, J. Colloid Interface Sci., 331 (1), 143-147.

[28] Ahmed, I., and Parish, R.V., 1993, Insoluble ligands and their applications: IV. Polysiloxane-bis(2aminoethyl)amine ligands and some derivatives, $J$. Organomet. Chem., 452 (1-2), 23-28.

[29] Nandi, M., Roy, P., Uyama, H., and Bhaumik, A., 2011, Functionalized mesoporous silica supported copper(II) and nickel(II) catalysts for liquid phase oxidation of olefins, Dalton Trans., 40 (46), 1251012518.

[30] Thuadaij, N., and Nuntiya, A., 2008, Synthesis and characterization of nanosilica from rice husk ash prepared by precipitation method, J. Nat. Sci., 7 (1), 59-65.

[31] El-Nahhal, I.M., El-Ashgar, N.M., Chehimi, M.M., Bargiela, P., Maquet, J., Babonneau, F., and Livage, J., 2003, Metal uptake by porous iminobis(N-2aminoethylacetamide)-modified polysiloxane ligand system, Microporous Mesoporous Mater., 65 (2-3), 299-310. 
[32] Hao, S., Zhong, Y., Pepe, F., and Zhu, W., 2012, Adsorption of $\mathrm{Pb}^{2+}$ and $\mathrm{Cu}^{2+}$ on anionic surfactanttemplated amino-functionalized mesoporous silicas, Chem. Eng. J., 189-190, 160-167.

[33] Harlick, P.J.E., and Sayari, A., 2007, Applications of pore-expanded mesoporous silica. 5. Triamine grafted material with exceptional $\mathrm{CO}_{2}$ dynamic and equilibrium adsorption performance, Ind. Eng. Chem. Res., 46 (2), 446-458.

[34] Akl, M.A., Kenawy, I.M.M., and Lasheen, R.R., 2004, Organically modified silica gel and flame atomic absorption spectrometry: Employment for separation and preconcentration of nine trace heavy metals for their determination in natural aqueous systems, Microchem. J., 78 (2), 143-156.

[35] Thommes, M., 2010, Physical adsorption characterization of nanoporous materials, Chem. Ing. Tech., 82 (7), 1059-1073.

[36] Samarghandi, M.R., Zarrabi, M., Sepehr, M.N., Panahi, R., and Foroghi, M., 2012, Removal of acid red 14 by pumice stone as a low-cost adsorbent: kinetic and equilibrium study, Iran. J. Chem. Chem.
Eng., 31 (3), 19-27.

[37] Anbalagan, K., Kumar, P.S., Gayatri, K.S., Hameed, S.S., Sindhuja, M., Prabhakaran, C., and Karthikeyan, R., 2015, Removal and recovery of $\mathrm{Ni}$ (II) ions from synthetic wastewater using surface modified Strychnos potatorum seeds: Experimental optimization and mechanism, Desalin. Water Treat., 53 (1), 171-182.

[38] Monier, M., Ayad, D.M., Wei, Y., and Sarhan, A.A., 2010, Adsorption of $\mathrm{Cu}(\mathrm{II}), \mathrm{Co}(\mathrm{II})$, and $\mathrm{Ni}(\mathrm{II})$ ions by modified magnetic chitosan chelating resin, $J$. Hazard. Mater., 177 (1-3), 962-970.

[39] Widjonarko, D.M., Jumina, Kartini, I., and Nuryono, 2014, Phosphonate modified silica for adsorption of $\mathrm{Co}(\mathrm{II}), \mathrm{Ni}(\mathrm{II}), \mathrm{Cu}(\mathrm{II})$ and $\mathrm{Zn}$ (II), Indones. J. Chem., 14 (2), 143-151.

[40] Wu, S., Wang, F., Yuan, H., Zhang, L., Mao, S., Liu, X., Alharbi, N.S., Rohani, S., and Lu, J., 2018, Fabrication of xanthate-modified chitosan/poly $(\mathrm{N}$ isopropylacrylamide) composite hydrogel for the selective adsorption of $\mathrm{Cu}(\mathrm{II}), \mathrm{Pb}(\mathrm{II})$ and $\mathrm{Ni}(\mathrm{II})$ metal ions, Chem. Eng. Res. Des., 139, 197-210. 